OPEN ACCESS

Edited by:

Anis Omri,

Qassim University, Saudi Arabia

Reviewed by:

Muntasir Murshed North South University, Bangladesh Kahia Montassar, LAREQUAD, Tunisia

${ }^{*}$ Correspondence:

Elena G. Popkova elenapopkova@yahoo.com

Specialty section: This article was submitted to Sustainable Energy Systems and Policies,

a section of the journal Frontiers in Energy Research

Received: 02 July 2021 Accepted: 28 October 2021 Published: 12 November 2021

Citation:

Popkova EG, Inshakova AO, Bogoviz AV and Lobova SV (2021) Energy Efficiency and Pollution Control Through ICTs for

Sustainable Development.

Front. Energy Res. 9:735551. doi: 10.3389/fenrg.2021.735551

\section{Energy Efficiency and Pollution Control Through ICTs for Sustainable Development}

\author{
Elena G. Popkova ${ }^{1 *}$, Agnessa O. Inshakova ${ }^{2}$, Aleksei V. Bogoviz ${ }^{3}$ and Svetlana V. Lobova ${ }^{4}$ \\ ${ }^{1}$ Moscow State Institute of International Relations, Moscow, Russia, ${ }^{2}$ Department of Civil and International Private Law of the \\ Institute of Law, Volgograd State University, Volgograd, Russia, ${ }^{3}$ Independent Researcher, Moscow, Russia, ${ }^{4}$ Economics and \\ Econometrics, Altai State University, Barnaul, Russia
}

The goal of this paper is to prove the necessity for a more thorough consideration and more active use of the modern ICTs for the technological support for the practical implementation of the SDGs' ecological block in the aspect of the increase of energy efficiency and environmental pollution control. The originality of this paper is as follows: it develops a proprietary methodology of evaluating the technical readiness (level of the development of ICTs) for implementing the ecological block of the SDGs, which envisage the increase of energy efficiency and the growth of environmental pollution control. The highest (but moderate) technological readiness to implement the ecological block of the SDGs among developed countries has been shown by Canada (14.42 points) and Denmark (11.03 points), among developing countries-China (7.72 points). As a result, it has been proved that UCTs are a perspective tool of the practical implementation of the ecological block of the SDGs, stimulating the increase of energy efficiency and improving the environment pollution control. For developed countries, it is recommended to increase the use of Big data and Al analytics by $90.36 \%$ and increase the use of ICTs in E-government by $89.74 \%$. This will allow achieving the growth of energy efficiency by $8.28 \%$ and the decrease of environmental pollution by $28.41 \%$. In developing countries, it is recommended to increase world robots distribution by $14.17 \%$ and increase the use of ICTs in E-government by $76.74 \%$. This will allow increasing the energy efficiency by $16.77 \%$ and decreasing the level of environmental pollution by $15.54 \%$. This paper's contribution to literature (innovative aspect of research) consists in filling the gap of the uncertainty (underdevelopment) of the tools for practical implementation of the SDGs ecological block. This paper has demonstrated the substantial potential of ICTs in the stimulation of the growth of energy efficiency and reduction of environmental pollution in developed and developing countries.

Keywords: energy efficiency, environmental pollution control, ICT, sustainable development, sdgs

\section{INTRODUCTION}

For most of the SDGs, the tools of their implementation are very clear, especially for the SDGs of the social block. For example, the implementation of SDG 4 envisages the increase of state financing of education at all levels of the educational system, i.e., the creation of additional statefinanced openings in educational establishments and the popularization of life-long learning. 
Similarly, the mechanism of implementing SDG 5, which is connected to the creation of gender-neutral jobs and an increase in the number of women in various professions and science, is obvious.

The problem is the uncertainty as to the provision of the practical implementation of the ecological block of the SDGs, which includes SDG 7, which envisages the increase of energy efficiency of the economy, and SDG 12, SDG 13, SDG 14, and SDG 15, which envisage the decrease of production waste. The tightening of ecological standards is a fragmentary measure, which ensures a partial, insufficient result for the above SDGs of the ecological block. Achievement of the full-scale result is impossible without proper ecological control.

The modern information and communication technologies (ICTs), which are based on the leading capabilities of the digital economy and Industry 4.0, allow achieving prominent results in implementing the SDGs of the ecological block (Popkova and Sergi, 2020). In the aspect of energy efficiency, digital sensors allow for a timely (in real-time) detection and liquidation of energy loss during its transportation (e.g., Smart Grid) (Dorokhova al., 2021). Energy-saving technologies stimulate the reduction of energy intensity of households and productions (Dhahri et al., 2021).

Alternative ("clean") energy was given a new push for development due to the expansion of automatization based on smart technologies, which allow-in the autonomous regime (without human participation)-switching between different sources of energy (depending on the current accessibility of renewable energy) (Magazzino et al., 2021; Ouyang and You, 2021; Overen et al., 2021).

This allows using "clean" energy when it is possible (when it is available) and during other periods-to prevent the energy deficit or automatically switch to non-renewable energy (Ghodbane et al., 2021; (Omri et al., 2021; Wang and Sun, 2021). This allows implementing alternative energy where its supply is unstable (e.g., unstable weather during the use of wind and solar energy). (Arif et al., 2021; Barış-Tüzemen et al., 2020; Murshed, 2020).

In the aspect of environmental pollution control, new ICTs ensure the continuous and wide monitoring of waste treatment at sanctioned dumps and the detection of unsanctioned dumps with the help of machine vision (based on the Internet of Things-IoT). Implementation of artificial intelligence (AI) allows companies to reduce production waste and learning new methods of their safe utilization. The wide use of ICTs in society (e.g., smartphones) also detecting the signs of violation of law in the sphere of environmental pollution and translating them into society, as well as passing them to the government via the e-government system (Bhujabal et al., 2021).

Based on the above, the following hypothesis $\left(\mathbf{H}_{\mathbf{0}}\right)$ is tested:

ICTs are a perspective tool of the practical implementation of the ecological block of the SDGs, stimulating the increase of energy efficiency and improving the environment pollution control.

This paper is to fill the gap of the uncertainty (lack of formation) of the tools for practical implementation of the SDGs ecological block. The purpose of this paper is to prove the necessity for a more thorough consideration and more active use of the modern ICTs for the technological support for the practical implementation of the SDGs ecological block in the aspect of the increase of energy efficiency and environmental pollution control.

The novelty of the research consists in the consideration and specification of the differences in using ICTs for increasing energy efficiency and environmental pollution control in developed and developing countries, the experience of which has been studied only partially and not systemically, which does not allow determining and taking into account the differences between them. The scientific and practical value of the paper and its contribution to literature consists in a previse quantitative measuring of the contribution of various ICTs to the increase of energy efficiency and environmental pollution control and selection of the most perspective ones to support the practical implementation of the SDGs ecological block.

The originality of this paper is due to the proprietary methodology of evaluating the technical readiness (level of the development of ICT) for implementing the ecological block of the SDGs, which envisage the increase of energy efficiency and the growth of environmental pollution control. The methodology's usefulness consists in the possibility to perform a national monitoring and international comparisons of the levels of the development of ICTs as a factor of energy efficiency and environmental pollution control.

The paper's uniqueness is due to the modelling (forecasting) of alternative scenarios of implementing the SDGs ecological block and developing the applied recommendations for the practical implementation of the optimistic scenario based on the use of ICT separately for developed and developing countries because of their specifics. After this introduction, the literature review is conducted, the methodology is described and the empirical basis of the research is given. The results include the following:

- Evaluation of the technological readiness of developed and developing countries to implement the ecological block of the SDGs;

- Scenario analysis of energy efficiency and environmental pollution in developed and developing countries for the period until 2030;

- Development of policy implications to optimize energy efficiency and environmental pollution control with the help of ICT in developed and developing countries for sustainable development.

The discussion section generalizes the research results and shows its contribution to policymaking. The article ends with a conclusion, where practical results, limitations and prospects for future scientific research are noted.

\section{LITERATURE REVIEW}

In general, the research problem has been studied in sufficient detail and is presented in the available scientific literature. The SDGs of the ecological block in many existing publications are 
considered separately from the SDGs of other blocks. However, the ecological block of the SDGs is studied inconsistently. Thus, energy efficiency issues are covered in the works of $\mathrm{Li}$ and $\mathrm{Du}$ (2021), Ma et al. (2021), Murshed and Alam (2021), Rubio et al. (2021), Touzani et al. (2021), Zeraibi et al. (2021). Pollution control issues have been investigated by scientists such as Azam et al. (2021), Du et al. (2021), Han et al. (2021), Rehman et al. (2021), and Wu et al. (2021).

At the same time, there is no holistic understanding of the SDGs of the ecological block as a scientific concept, which is a research gap. Also, the tools for the practical implementation of the environmental block of the SDGs are poorly studied and clearly not defined, which another gap in the literature is.

Certain issues of using ICT for sustainable development, in particular, for the implementation of some of the SDGs of the ecological block, are considered in the publications of Adam et al. (2020), Arshad et al. (2020), Murshed et al. (2020), Ruscio et al. (2021), Wen et al. (2021). However, the overall contribution of ICTs to the implementation of the SDGs of the ecological block and its features in developed and developing countries are not well understood, which also serves as a research gap. It should also be noted that the replicability of the results obtained in previous studies is difficult due to the reliance on "narrow" and inaccessible national statistics.

All the noted research gaps are comprehensively filled in this article, where ICT is considered as a potential tool for ensuring energy efficiency and environmental pollution control-that is, the implementation of the SDGs of the environmental block-in the interests of sustainable development with an in-depth (separately) study of the experience and prospects of developed and developing countries.

\section{METHODS}

\section{The Methodology of Regression Analysis Used During the Research}

The methodological apparatus of this study, which ensures the verification of the hypothesis put forward, is based on regression analysis - the most reliable and accurate method of economic statistics. The set goal has predetermined the logic and structure of this research. In the first part, regression analysis is used to determine the contribution of various ICTs to the provision of energy efficiency and environmental pollution control. The indicator of energy efficiency is the Energy Trilemma Index, which is calculated by World Energy Council (2021), and the indicator of environmental pollution control is the pollution index, which is calculated by Numbeo (2021). The perspective ICTs, which potentially stimulate the growth of energy efficiency and improvement of environmental pollution control are as follows.

First, the general level of the use of ICTs in society (level of development of information society and E-Participation). Here we speak of widely accessible and popular user ICT: computer technology, smartphones, and the Internet. A high level of the use of ICTs on society allows-in case of the interested public detecting the cases of violation of ecological law (e.g., energy disasters/catastrophes such as oil or gas leaks, or unsanctioned dumps or unsafe utilization of production and consumption waste) gathering digital data on these violations (photo, audio, and video) and translating these data via the Internet. The data could be transferred to the state regulator in the sphere of ecological control via the websites of online feedback and the representative of civil society, as well as wide groups of population (via specialized websites of responsible consumption, social networks, etc.); Second, robotization of production in the economy (World robots distribution). Robotized productions could use energy-saving technologies. In this case, robotization might even decrease the energy intensity of productions as compared to mechanization or manual labour. In addition to this, robot technologies allow for continuous and total control of energy consumption. In the aspect of production waste, robotization allows developing an automatized secure utilization of waste that is deeply built-in business processes.

Third, the use of Big data and AI analytics (Use of Big data and analytics). Together with the Internet of Things (IoT), these ICTs allow forming cyber-physical systems at responsible productions. Being unified in one complex of machine vision, the above ICTs provide a systemic automatized monitoring of energy consumption and production waste in entrepreneurship. In addition to this, the technologies of Big data and AI analytics allow for the automatic formation of corporate ecological reports, in particular, with information on energy efficiency and production waste, and sending it to controlling bodies and posting on the Internet for wide review.

Fourth, the level of E-government development. E-government allows for the automatized ecological monitoring and control. Based on e-government, the rankings of companies' contribution to the implementation of the SDGs ecological block in the aspect of their energy efficiency and production waste could be formed. Also, intellectual analysis of corporate ecological reports with the use of AI could be performed, as well as electronic acceptance of feedback from interested parties and companies regarding the violations of environmental law.

Fifth, the level of using (readiness to use) drones (Autonomous Vehicle Readiness Index). Unmanned transport includes drones, which allow for remote ecological monitoring and control. This could be useful for the independent control of energy efficiency and environmental pollution by the representatives of civil society and the bodies of government ecological control, as well as for corporate ecological reports. For example, in the activities of hazardous productions, which are automatized (to avoid risks for employees' health), unmanned transport allows collecting data on energy efficiency and environment pollution and forming a digital database of managerial data.

Regression analysis is to determine regression equations that reflect the positive influence of ICTs on energy efficiency and environmental pollution control. For this, the circle of independent variables is narrowed down, and the variables with negative influence are removed. 


\section{The Proprietary Methodology of Evaluating the Technical Readiness (for Implementing the Ecological Block of the SDGs)}

This paper develops and uses a proprietary methodology of evaluating the technical readiness (level of the development of ICTs) for implementing the SDGs ecological block, which envisages the increase of energy efficiency and the growth of environmental pollution control. The methodology is based on T.L. Saaty's hierarchy process and envisages the following sequence of actions:

1. Calculating weight coefficients separately for developed and developing countries. Weight coefficient is the ratio of the sum of regression coefficients of both resulting variables with the set factor variable to the total sum of all weight coefficients (sums' absolute values are used). The sum of weight coefficients (measured in fractions of 1) for each category of countries equals 1 ;

2. Calculating the ratio of the indicator's factual value for a country to the maximum possible value;

3. Calculating weighted sums as a product of ratios to the maximum and weight coefficients;

4. Calculating hierarchical synthesis as a sum of weighted sums.

The above methodology is used to evaluate the technological readiness of developed and developing countries for implementing the ecological block of the SDGs.

\section{The Empirical Basis of the Research}

A sample of eight developed and eight developing countries, for which the values of the above indicators are available, has been formed for the research.

At the second stage of the research, the scenario analysis of energy efficiency and environmental pollution in developed and developing countries for the period until 2030 is performed. The monte Carlo method is used to compile the forecasts of energy efficiency and environmental pollution in developed and developing countries for the period until 2030. The third stage includes the development of policy implications to optimize energy efficiency and environmental pollution control with the help of ICT in developed and developing countries for sustainable development. The polycriterial optimization with the help of the simplex method is conducted.

\section{RESULTS}

\section{Evaluation of the Technological Readiness of Developed and Developing Countries to Implement the Ecological Block of the SDGs}

As a result of multiple repeats of the automatic compilation of regression equations, all factor variables with negative influence are eliminated, and the following final regression equations are obtained:

$$
\text { EEddc }=86.04-0.54 \mathrm{ict}_{3}-0.16 \mathrm{ict}_{4}
$$

According to the above regression equation, an increase of the level of use of Big data and AI analytics by 1 position leads to an increase of energy efficiency of developed countries by 0.54 points. An increase of the use of ICTs in E-government by 1 position leads to an increase of energy efficiency of developed countries by 0.16 points.

$$
\text { PLddc }=20.94+0.93 \text { ict }_{3}
$$

According to the obtained regression equation, an increase of the level of use of big data and AI analytics by 1 position leads to a decrease of the volume of environment pollution in developed countries by 0.93 points.

$$
\text { EEdgc }=85.63-0.08 \text { ict }_{2}-0.37 \text { ict }_{4}
$$

According to the obtained regression equation, an increase of world robots distribution by position leads to an increase of energy efficiency of developed countries by 0.08 points. An increase of the use of ICTs in E-government leads by 1 position leads to an increase of energy efficiency of developed countries by 0.16 points.

$$
\text { PLdgc }=53.10+0.34 \text { ict }_{4}
$$

According to the obtained regression equation, an increase of the use of ICTs in E-government by 1 position leads to a decrease of the volume of environment pollution in developing countries by 0.34 points.

Thus, the sum (in absolute value) of regression coefficients in equations for developed countries equals $(0.54+0.93)+0.16=$ $1.47+0.16=1.63$. The weight coefficient for ict $_{3}=1.47 / 1.63=$ 0.90 , and for ict ${ }_{4}=0.16 / 1.63=0.10$. The sum (in absolute value) of regression coefficients in equations for developing countries is $0.08+(0.37+0.34)=0.08+0.71=0.79$. Weight coefficient for ict 2 $=0.08 / 0.79=0.10$, and for ict ${ }_{4}=0.71 / 0.79=0.90$.

All selected (which positively influence the resulting variables) factor variables are measured in positions from 1 to 63. That's why the maximum values in all cases equal 63 . Since for the values of the selected factor variables, the "the lower the better" rule is true when calculating the ratio to the maximum it is expedient to calculate the ratio of the maximum (63) to factual values.

Thus, for example, in Russia, ict ${ }_{2}=32$. Ratio to the maximum: $63 / 32=1.97 ;$ ict $_{4}=33$. Ratio to the maximum: $63 / 33=1.91$. Weighted sum for ict ${ }_{2}=1.977^{\star} 0.10=0.20$; for ict $_{4}$ $=1.91^{\star} 0.90=1.72$. Hierarchical synthesis: $0.20+1.72=1.92$ (low readiness). The detailed calculation of hierarchical synthesis for all countries of the sample is performed in Supplementary Table S1. Its results are demonstrated in Figure 1.

As shown in Figure 1, developed countries demonstrate higher technological readiness to implement the ecological block of the SDGs. Thus, the highest value of hierarchical synthesis is observed in Canada (14.42 points-moderate readiness), Denmark (11.03 points-moderate readiness), and Norway (9.93 points-moderate readiness). Among developing countries, the highest readiness is demonstrated by China ( 7.72 points-moderate readiness). 
Developed countries

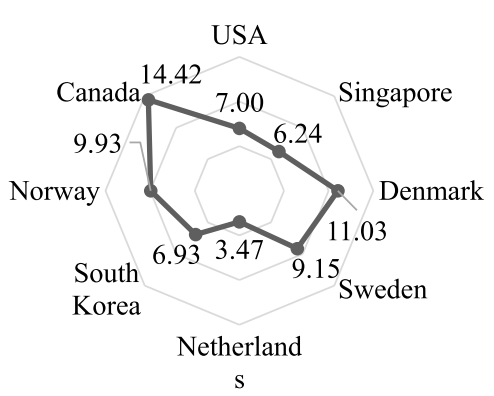

Developing countries

UAE

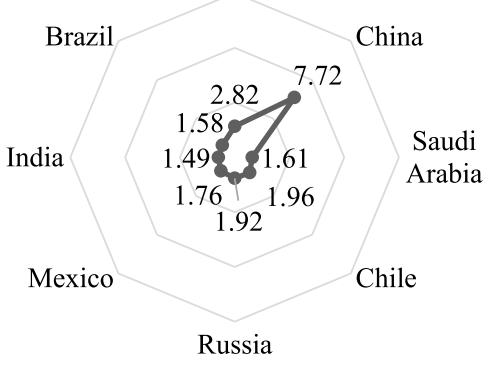

FIGURE 1 | Assessment of the technological readiness of developed and developing countries to implement the ecological block of the SDGs in 2020 , points 1-63.

TABLE 1 | Energy efficiency, environment pollution, and the ICTs factors that potentially influence them in developed and developing countries in 2020.

\begin{tabular}{|c|c|c|c|c|c|c|c|c|}
\hline \multirow[t]{3}{*}{$\begin{array}{l}\text { Category of } \\
\text { countries }\end{array}$} & \multirow[t]{3}{*}{ Country } & \multicolumn{2}{|c|}{$\begin{array}{l}\text { Results in the sphere of } \\
\text { energy efficiency and } \\
\text { environmental pollution }\end{array}$} & \multicolumn{5}{|c|}{$\begin{array}{l}\text { Factors of ICTs that potentially contribute to the increase of energy efficiency and } \\
\text { environmental pollution control }\end{array}$} \\
\hline & & $\begin{array}{c}\text { Energy } \\
\text { trilemma } \\
\text { index } \\
\text { points } \\
1-100\end{array}$ & $\begin{array}{l}\text { Pollution } \\
\text { index } \\
\text { points } \\
0-200\end{array}$ & $\begin{array}{c}\text { E-Participation } \\
\text { position } \\
1-63\end{array}$ & $\begin{array}{l}\text { World robots } \\
\text { distribution } \\
\text { position } \\
1-63\end{array}$ & $\begin{array}{l}\text { Use of big } \\
\text { data and } \\
\text { analytics }{ }^{b} \text {, } \\
\text { position } \\
1-63\end{array}$ & $\begin{array}{l}\text { E-Government }{ }^{\mathrm{b}} \text {, } \\
\text { position } \\
1-63\end{array}$ & $\begin{array}{l}\text { Autonomous } \\
\text { vehicle } \\
\text { readiness } \\
\text { index }{ }^{\mathrm{a}}, \\
\text { points } 0-100\end{array}$ \\
\hline & & EE & PL & ict $_{1}$ & ict $_{2}$ & ict $_{3}$ & ict $_{4}$ & ict $_{5}$ \\
\hline \multirow{8}{*}{$\begin{array}{l}\text { Developed } \\
\text { countries (ddc) }\end{array}$} & United States & 79.8 & 38.89 & 1 & 4 & 9 & 9 & 23.99 \\
\hline & Singapore & 70.5 & 33.16 & 6 & 15 & 10 & 11 & 25.45 \\
\hline & Denmark & 84.0 & 20.40 & 9 & 30 & 12 & 1 & 21.21 \\
\hline & Sweden & 84.2 & 18.44 & 35 & 18 & 7 & 6 & 23.17 \\
\hline & Netherlands & 76.6 & 25.28 & 9 & 21 & 20 & 10 & 25.22 \\
\hline & South Korea & 73.4 & 61.85 & 1 & 3 & 15 & 2 & 22.71 \\
\hline & Norway & 80.5 & 18.14 & 18 & 42 & 6 & 13 & 24.25 \\
\hline & Canada & 81.5 & 28.13 & 16 & 13 & 4 & 26 & 20.68 \\
\hline \multirow[t]{8}{*}{$\begin{array}{l}\text { Developing } \\
\text { countries (dgc) }\end{array}$} & $\begin{array}{l}\text { United Arab } \\
\text { Emirates }\end{array}$ & 69.7 & 50.44 & 16 & 53 & 2 & 21 & 22.23 \\
\hline & China & 67.0 & 81.47 & 9 & 1 & 8 & 40 & 16.42 \\
\hline & Saudi Arabia & 67.0 & 64.13 & 51 & 52 & 24 & 38 & 22.23 \\
\hline & Chile & 71.7 & 78.96 & 28 & 48 & 56 & 31 & 11.28 \\
\hline & Russia & 73.8 & 62.32 & 26 & 32 & 33 & 33 & 11.45 \\
\hline & Mexico & 69.6 & 61.24 & 35 & 10 & 51 & 50 & 7.42 \\
\hline & India & 56.2 & 79.62 & 28 & 12 & 32 & 59 & 6.95 \\
\hline & Brazil & 74.9 & 54.53 & 18 & 17 & 58 & 47 & 5.49 \\
\hline
\end{tabular}

Created by the authors based on IMD (2021), KPMG (2020), Numbeo (2021), and World Energy Council (2021).

'The higher the indicators' value, the better.

${ }^{b}$ The lower the indicator's value, the better.

\section{Scenario Analysis of Energy Efficiency and Environmental Pollution in Developed and Developing Countries for the Period Until 2030}

For the scenario analysis of energy efficiency and environmental pollution in developed and developing countries, the forecasts of the corresponding indicators for the period until 2030 are created. According to materials from Table 1 , arithmetic means $\left(\mathrm{x}_{\mathrm{md}}\right)$ and standard deviations (sd) are calculated:
- in developed countries for $\mathrm{EE} \mathrm{x}_{\mathrm{md}}=78.81$, sd $=4.93$; for $\mathrm{PL}$ $\mathrm{x}_{\mathrm{md}}=30.54, \mathrm{sd}=14.61$;

- in developing countries for $\mathrm{EE}_{\mathrm{md}}=68.74$, $\mathrm{sd}=5.82$; for $\mathrm{PL}$ $\mathrm{x}_{\mathrm{md}}=66.59, \mathrm{sd}=11.97$.

With a normal distribution, 100 random numbers according to the obtained arithmetic means and standard deviations are received for each (Supplementary Table S2). The histograms of the normal distribution of the forecast $\mathrm{EE}$ and PL values in developed and developing countries for the period until 2030 are 
TABLE 2 | Scenarios of energy efficiency and environmental pollution in developed and developing countries for the period until 2030.

\begin{tabular}{|c|c|c|c|c|c|}
\hline \multirow[t]{2}{*}{ Scenario } & \multirow[t]{2}{*}{ Indicator } & \multicolumn{2}{|c|}{$\begin{array}{l}\text { Developed } \\
\text { countries }\end{array}$} & \multicolumn{2}{|c|}{$\begin{array}{l}\text { Developing } \\
\text { countries }\end{array}$} \\
\hline & & EE & PL & EE & PL \\
\hline \multicolumn{2}{|c|}{ Basic value in 2020 , points } & 78.81 & 30.54 & 68.74 & 66.59 \\
\hline \multirow[t]{3}{*}{ Pessimistic } & Probability of the scenario, \% & 5 & 17 & 19 & 6 \\
\hline & Value according to the scenario, points & 71.73 & 50.18 & 64.44 & 88.42 \\
\hline & Growth of the value according to the scenario as compared to the value in $2020, \%$ & -8.98 & 64.31 & -6.26 & 32.78 \\
\hline \multirow[t]{3}{*}{ Realistic } & Probability of the scenario, \% & 17 & 32 & 23 & 23 \\
\hline & Value according to the scenario, points & 83.41 & 40.16 & 67.60 & 66.97 \\
\hline & Growth of the value according to the scenario as compared to the value in $2020, \%$ & 5.84 & 31.50 & -1.66 & 0.57 \\
\hline \multirow[t]{3}{*}{ Optimistic } & Probability of the scenario, \% & 6 & 6 & 7 & 9 \\
\hline & Value according to the scenario, points & 88.08 & 10.10 & 80.27 & 56.24 \\
\hline & Growth of the value according to the scenario as compared to the value in $2020, \%$ & 11.76 & -66.93 & 16.77 & -15.54 \\
\hline
\end{tabular}

shown in Supplementary Figures S2-S4. Based on these histograms, the values of energy efficiency (EE) and environment pollution (PL) are calculated for the following scenarios (forecast values with the probability exceeding 5\%):

- pessimistic scenario, at which energy efficiency is the lowest $(\mathrm{EE} \rightarrow \mathrm{min})$, and environment pollution is the highest $(\mathrm{PL} \rightarrow \max )$;

- realistic scenario, at which the values of energy efficiency (EE) and environment pollution (PL) with the highest probability are used;

- optimistic scenario, at which energy efficiency is the highest $(\mathrm{EE} \rightarrow \max )$, and environment pollution is the lowest $(\mathrm{PL} \rightarrow \min )$;

The results of the scenario analysis are demonstrated in Table 2.

Table 2 shows that in the pessimistic scenario, energy efficiency will decrease in developed countries by $8.98 \%$ until 2030 , as compared to the 2020 level, and in developing countries by $6.26 \%$. The level of environmental pollution will grow in developed countries by $64.31 \%$, and in developing countries - by $32.78 \%$. In the realistic scenario, energy efficiency in developed countries will grow by $5.84 \%$ until 2030 , and in developing countries, it will decrease by $1.66 \%$. The level of environmental pollution will grow in developed countries by $31.50 \%$, and in developing countries - by $0.57 \%$, i.e., it will remain almost unchanged.

In the optimistic scenario, energy efficiency will grow in developed countries by $11.76 \%$ until 2030 , and in developing countries-by $16.77 \%$. The level of environmental pollution will decrease in developed countries by $66.93 \%$ and in developing countries by $15.54 \%$. This scenario is the most favourable and desirable one. However, taking into account its low probability (6-9\%), one should not expect its implementation in practice without the adoption of special managerial measures.

Policy implications to optimize energy efficiency and environmental pollution control with the help of ICT in developed and developing countries for sustainable development.
For the regulatory support for the practical implementation of the optimistic scenario of energy efficiency and environmental pollution in developed and developing countries for the period until 2030 based on regression Eqs 1-4, the simplex method is used to obtain the optimal values of the ICT factors in developed and developing countries (Figure 2).

The results obtained in Figure $\mathbf{2}$ allow offering the following policy implications to optimize energy efficiency and environmental pollution control with the help of ICTs in countries for sustainable development. In developed countries, it is recommended to increase the use of Big data and AI analytics by $90.36 \%$ and the use of ICTs in E-government by $89.74 \%$.

For the two above indicators, developed countries should have the first position in the world. However, even in this case, the optimistic scenario will not be implemented fully-an increase of energy efficiency by $8.28 \%$ (instead of $11.76 \%$ ) and a decrease of environment pollution by $28.41 \%$ (instead of $66.93 \%$ ) will be achieved.

In developing countries, it is recommended to increase world robots distribution by $14.17 \%$ (up to 24.14 th position) and the use of ICTs in E-government by $76.74 \%$ (up to 9.29th position). This will allow for the full implementation of the optimistic scenario through managing the development of ICTs.

Thus, the results obtained revealed serious differences between the contribution of ICTs to the implementation of the SDGs of the ecological block in developed and developing countries. The results also made it possible to form different management approaches to the implementation of the SDGs of the ecological block in both considered categories of countries on the basis of flexible regulation of ICT development. For the first time, the contradictory influence of ICT in the implementation of the SDGs of the ecological block was proved, and the features of developed and developing countries were clarified.

\section{DISCUSSION}

Thus, the results of the performed research have proved the hypothesis $\left(\mathrm{H}_{0}\right)$ and conformed that ICTs are a perspective tool of 

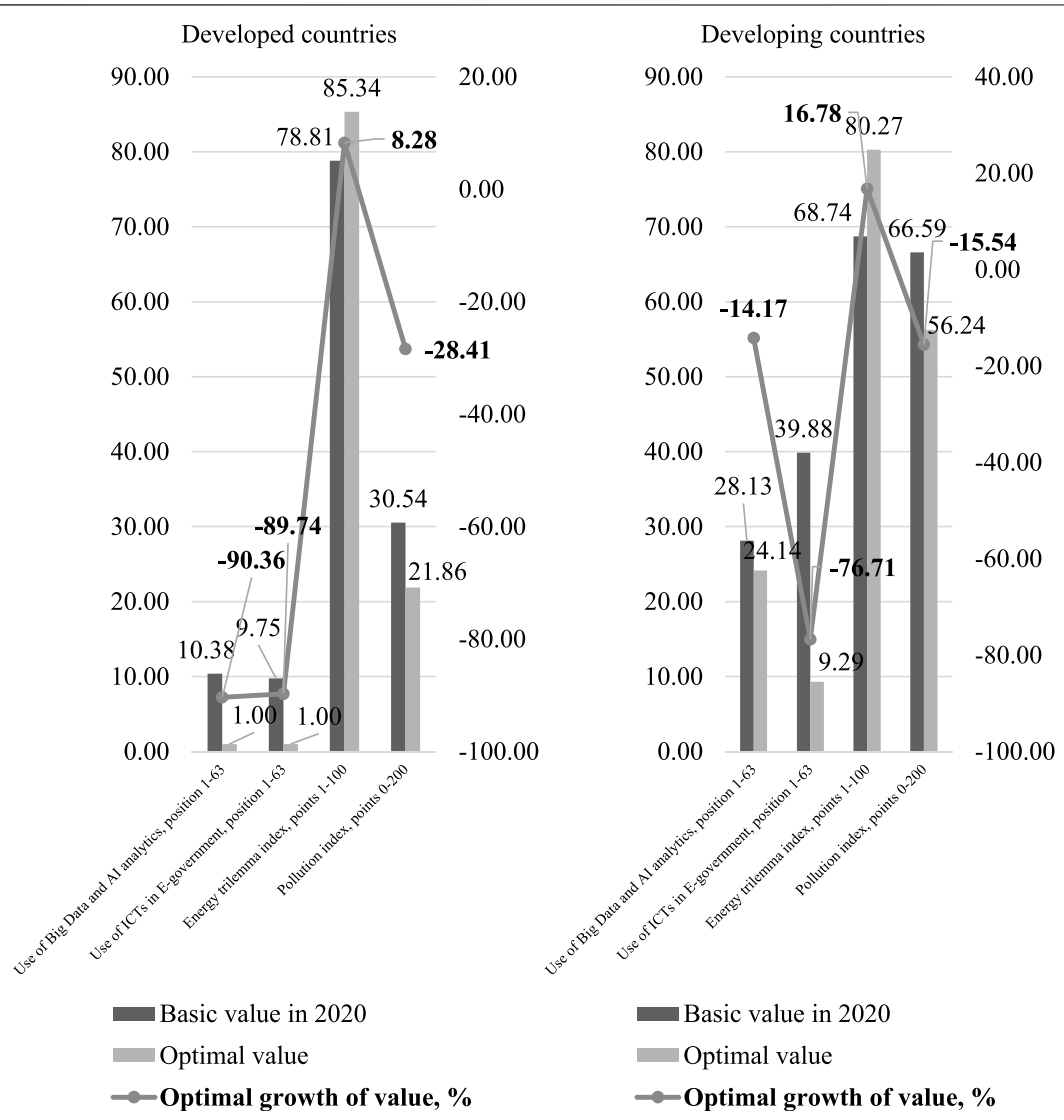

FIGURE 2 | The optimal influence of the ICT factors to increase energy efficiency and environmental pollution control in the period until 2030.

the practical implementation of the ecological block of the SDGs, stimulating the increase of energy efficiency and improving the environment pollution control.

However, it has been determined that not all ICTs contribute to implementing the ecological block of the SDGs, and most perspective ICTs differ in developed and developing countries. In both cases, the contribution is due to the use of ICTs in E-government, which is a universal tool for implementing the ecological block of the SDGs. In addition to it, a perspective tool in developed countries is the use of Big data and AI analytics, and in developing countries-robotization. The highest (but moderate) technological readiness to implement the ecological block of the SDGs among developed countries is demonstrated by Canada (14.42 points) and Denmark (11.03 points), and among developing countries-China (7.72 points).

The necessity for a more thorough consideration and more active use of modern ICTs for the technological support for the practical implementation of the ecological block of the SDGs is explained by the fact that without implementing special managerial measures by 2030, energy efficiency in developed countries might not grow, and in developing countries-decrease by $1.66 \%$, while in developed countries there is a high probability of the growth of environmental pollution by $31.50 \%$ (realistic scenario).

To avoid this and to implement the less probable optimistic scenario in developed countries, it is recommended to increase the use of Big data and AI analytics by $90.36 \%$ and increase the use of ICTs in E-government by $89.74 \%$. This will allow achieving an increase of energy efficiency by $8.28 \%$ and a decrease of environment pollution by $28.41 \%$. In developing countries, it is recommended to increase world robots distribution by $14.17 \%$ and increase the use of ICTs in E-government by $76.74 \%$. Due to this, energy efficiency will grow by $16.77 \%$, and the level of environmental pollution will reduce by $15.54 \%$.

This paper's contribution to literature consists in filling the gap of the uncertainty (underdevelopment) of the tools for practical implementation of the SDGs ecological block. This paper has demonstrated the substantial potential of ICTs in the stimulation of the growth of energy efficiency and reduction of environmental pollution in developed and developing countries. The practical significance of the results obtained is to clarify the prospects and develop empirical recommendations for state regulation of the implementation of the SDGs of the ecological block in developed and developing countries. 


\section{CONCLUSION}

Thus, the proposed hypothesis $\left(\mathrm{H}_{0}\right)$ received scientific confirmation. The results of this article proved that ICT is a promising tool for the practical implementation of the environmental block of the SDGs, stimulating energy efficiency and improving environmental pollution control. The policy implications and results of this study include:

- Justification of the need to apply different management approaches to the implementation of the SDGs of the ecological block in developed and developing countries;

- Proposal and justification of the advisability of using certain applied ICT tools for the implementation of the SDGs of the environmental block in developed and developing countries;

- The risks of using ICT in developed and developing countries were identified and applied recommendations were proposed for managing these risks in the interests of a balanced implementation of the SDGs of the environmental block in both categories of countries.

The advantage of the study is complete and free replicability due to the reliance on official international statistics from open sources - all data are given in the tables of this article.

However, the research has shown that in developed countries, the existing large perspectives of increase of energy efficiency and decrease of environmental pollution cannot be fully implemented with the foundation only on ICTs. This show the limited capabilities of ICTs in the stimulation of implementation of

\section{REFERENCES}

Adam, I. O., Alhassan, M. D., and Afriyie, Y. (2020). What Drives Global B2C E-Commerce? an Analysis of the Effect of ICT Access, Human Resource Development and Regulatory Environment. Technol. Anal. Strateg. Manage. 32 (7), 835-850. doi:10.1080/09537325.2020.1714579

Arif, S., Taweekun, J., Ali, H. M., and Theppaya, T. (2021). Techno Economic Evaluation and Feasibility Analysis of a Hybrid Net Zero Energy Building in Pakistan: A Case Study of Hospital. Front. Energ. Res. 9. doi:10.3389/ fenrg.2021.668908

Arshad, Z., Robaina, M., and Botelho, A. (2020). The Role of ICT in Energy Consumption and Environment: an Empirical Investigation of Asian Economies with Cluster Analysis. Environ. Sci. Pollut. Res. 27 (26), 32913-32932. doi:10.1007/s11356-020-09229-7

Azam, A., Rafiq, M., Shafique, M., and Yuan, J. (2021). Does Nuclear or Renewable Energy Consumption Help to Control Environmental Pollution? New Evidence from China. Renew. Energ. Focus 39, 139-147. doi:10.1016/j.ref.2021.08.002

Barış-Tüzemen, Ö., Tüzemen, S., and Çelik, A. K. (2020). Does an N-Shaped Association Exist between Pollution and ICT in Turkey? ARDL and Quantile Regression Approaches. Environ. Sci. Pollut. Res. 27 (17), 20786-20799. doi:10.1007/s11356-020-08513-w

Bhujabal, P., Sethi, N., and Padhan, P. C. (2021). ICT, Foreign Direct Investment and Environmental Pollution in Major Asia Pacific Countries. Environ. Sci. Pollut. Res. 28, 42649-42669. doi:10.1007/ s11356-021-13619-w

Dhahri, S., Slimani, S., and Omri, A. (2021). Behavioural Entrepreneurship for Achieving Sustainable Development Goals. Technol. Forecast. Soc. Change 165. doi:10.1016/j.techfore.2020.120561.Get.rights.and.content the SDGs ecological block developed countries, which is a research limitation. In future studies, it is expedient to pay attention to the search for additional tools for developed countries.

\section{DATA AVAILABILITY STATEMENT}

The original contributions presented in the study are included in the article/Supplementary Material, further inquiries can be directed to the corresponding author.

\section{AUTHOR CONTRIBUTIONS}

All authors contributed equally to the paper.

\section{FUNDING}

This work was supported by Russian Science Foundation (No. 2018-00314).

\section{SUPPLEMENTARY MATERIAL}

The Supplementary Material for this article can be found online at: https://www.frontiersin.org/articles/10.3389/fenrg.2021.735551/ full\#supplementary-material

Dorokhova, M., Ribeiro, F., Barbosa, A., Viana, J., Soares, F., and Wyrsch, N. (2021). Real-world Implementation of an ICT-Based Platform to Promote Energy Efficiency. Energies 14 (9), 2416. doi:10.3390/en14092416

Du, H., Guo, Y., Lin, Z., Qiu, Y., and Xiao, X. (2021). Effects of the Joint Prevention and Control of Atmospheric Pollution Policy on Air PollutantsA Quantitative Analysis of Chinese Policy Texts. J. Environ. Manage. 300, 113721. doi:10.1016/j.jenvman.2021.113721

Ghodbane, M., Bellos, E., Said, Z., Boumeddane, B., Hussein, A. K., and Kolsi, L. (2021). Evaluating Energy Efficiency and Economic Effect of Heat Transfer in Copper Tube for Small Solar Linear Fresnel Reflector. J. Therm. Anal. Calorim. 143, 4197-4215. doi:10.1007/s10973-020-09384-6

Han, C., Xu, R., Zhang, Y., Yu, W., Zhang, Z., Morawska, L., et al. (2021). Air Pollution Control Efficacy and Health Impacts: A Global Observational Study from 2000 to 2016. Environ. Pollut. 287, 117211. doi:10.1016/j.envpol.2021.117211

IMD (2021). World Digital Competitiveness Ranking 2020. E. coli. Available from: https://www.imd.org/centers/world-competitiveness-center/rankings/worlddigital-competitiveness/(Accessed June 23, 2021).

KPMG (2020). 2020 Autonomous Vehicles Readiness Index. E. coli. Available from: https:/home.kpmg/uk/en/home/insights/2020/07/2020-autonomousvehicles-readiness-index.html (Accessed June 23, 2021).

Li, M., and Du, W. (2021). Can Internet Development Improve the Energy Efficiency of Firms: Empirical Evidence from China. Energy 237, 121590. doi:10.1016/j.energy.2021.121590

Ma, Q., Murshed, M., and Khan, Z. (2021). The Nexuses between Energy Investments, Technological Innovations, Emission Taxes, and Carbon Emissions in China. Energy Policy 155, 112345. doi:10.1016/j.enpol.2021.112345

Magazzino, C., Porrini, D., Fusco, G., and Schneider, N. (2021). Investigating the Link Among ICT, Electricity Consumption, Air Pollution, and Economic Growth in EU Countries. Energ. Sourc. B: Econ. Plann. Pol., 1-23. doi:10.1080/15567249.2020.1868622 
Murshed, M., and Alam, M. S. (2021). Estimating the Macroeconomic Determinants of Total, Renewable, and Non-renewable Energy Demands in Bangladesh: the Role of Technological Innovations. Environ. Sci. Pollut. Res. 28, 30176-30196. doi:10.1007/s11356-021-12516-6

Murshed, M. (2020). An Empirical Analysis of the Non-linear Impacts of ICTTrade Openness on Renewable Energy Transition, Energy Efficiency, Clean Cooking Fuel Access and Environmental Sustainability in South Asia. Environ. Sci. Pollut. Res. 27 (29), 36254-36281. doi:10.1007/s11356-020-09497-3

Murshed, M., Chadni, M. H., and Ferdaus, J. (2020). Does ICT Trade Facilitate Renewable Energy Transition and Environmental Sustainability? Evidence from Bangladesh, India, Pakistan, Sri Lanka, Nepal and Maldives. Energ. Ecol. Environ. 5, 470-495. doi:10.1007/s40974-020-00190-2

Numbeo (2021). Quality of Life Index by Country 2021. E. coli. Available from: https://www.numbeo.com/quality-of-life/rankings_by_country.jsp (Accessed June 23, 2021).

Omri, A., Kahia, M., and Kahouli, B. (2021). Does Good Governance Moderate the Financial development-CO2 Emissions Relationship. Environ. Sci. Pollut. Res. 28, 47503-47516. doi:10.1007/s11356-021-14014-1

Ouyang, L., and You, D. (2021). The Green Innovation Effect on Heavy-Polluting Enterprises under the Environmental Protection Law. Front. Energ. Res. 9. doi:10.3389/fenrg.2021.681334

Overen, O. K., Meyer, E. L., and Makaka, G. (2021). Passive Solar and Conventional Housing Design: A Comparative Study of Daylighting Energy Efficiency Potential. Front. Energ. Res. 9. doi:10.3389/ fenrg.2021.668906

Popkova, E. G., and Sergi, B. S. (2021). Energy Efficiency in Leading Emerging and Developed Countries. Energy 221 (1), 119730. doi:10.1016/j.energy.2020.119730

Rehman, A., Ma, H., Ozturk, I., Murshed, M., and Dagar, V. (2021). The Dynamic Impacts of CO2 Emissions from Different Sources on Pakistan's Economic Progress: a Roadmap to Sustainable Development. Environ. Dev. Sustain.. doi:10.1007/s10668021-01418-9

Rubio, F., Llopis-Albert, C., and Valero, F. (2021). Multi-objective Optimization of Costs and Energy Efficiency Associated with Autonomous Industrial Processes for Sustainable Growth. Technol. Forecast. Soc. Change 173, 121115. doi:10.1016/ j.techfore.2021.121115

Ruscio, F., Peralta, G., Pollini, L., and Costanzi, R. (2021). Information Communication Technology (ICT) Tools for Preservation of Underwater Environment: A VisionBased Posidonia Oceanica Monitoring. Mar. Technol. Soc. J 55 (4), 11-23. doi:10.4031/MTSJ.55.4.5
Touzani, S., Prakash, A. K., Wang, Z., Agarwal, S., Pritoni, M., Kiran, M., et al. (2021). Controlling Distributed Energy Resources via Deep Reinforcement Learning for Load Flexibility and Energy Efficiency. Appl. Energ. 304, 117733. doi:10.1016/ j.apenergy.2021.117733

Wang, H., and Sun, B. (2021). Diffusion Mechanism of Leading Technology in the New Energy Industry Based on the Bass Model. Front. Energ. Res. 9. doi:10.3389/fenrg.2021.586787

Wen, H., Lee, C.-C., and Song, Z. (2021). Digitalization and Environment: How Does ICT Affect enterprise Environmental Performance?. Environ. Sci. Pollut. Res. 28, 54826-54841. doi:10.1007/s11356-021-14474-5

World Energy Council (2021). World Energy Trilemma Index 2020. E. coli. Available from: https://trilemma.worldenergy.org/(Accessed June 23, 2021).

Wu, W., Wang, W., Zhang, L., Wang, Q., Wang, L., and Zhang, M. (2021). Does the Public Haze Pollution Concern Expressed on Online Platforms Promoted Pollution Control? - Evidence from Chinese Online Platforms. J. Clean. Prod. 318, 128477. doi:10.1016/j.jclepro.2021.128477

Zeraibi, A., Balsalobre-Lorente, D., and Murshed, M. (2021). The Influences of Renewable Electricity Generation, Technological Innovation, Financial Development, and Economic Growth on Ecological Footprints in ASEAN-5 Countries. Environ. Sci. Pollut. Res. 28, 51003-51021. doi:10.1007/s11356-02114301-x

Conflict of Interest: The authors declare that the research was conducted in the absence of any commercial or financial relationships that could be construed as a potential conflict of interest.

Publisher's Note: All claims expressed in this article are solely those of the authors and do not necessarily represent those of their affiliated organizations, or those of the publisher, the editors and the reviewers. Any product that may be evaluated in this article, or claim that may be made by its manufacturer, is not guaranteed or endorsed by the publisher.

Copyright (c 2021 Popkova, Inshakova, Bogoviz and Lobova. This is an open-access article distributed under the terms of the Creative Commons Attribution License (CC BY). The use, distribution or reproduction in other forums is permitted, provided the original author(s) and the copyright owner(s) are credited and that the original publication in this journal is cited, in accordance with accepted academic practice. No use, distribution or reproduction is permitted which does not comply with these terms. 